\title{
Manipulating Nonradiative Decay Channel by Intermolecular Charge Transfer for Exceptionally- Improved Photothermal Conversion
}

Wenbo Hu, ,t,\$,\& Xiaofei Miao, ,,\& Haojie Tao, ${ }^{\dagger}$ Alexander Baev, ${ }^{\S}$ Can Ren, "Quli Fan, *,;,\# Tingchao He *,/ Wei Huang ${ }^{\dagger, t, \#}$ and Paras N. Prasad*,\$

†Key Laboratory for Organic Electronics and Information Displays \& Institute of Advanced Materials (IAM), Nanjing University of Posts \& Telecommunications, Nanjing 210023, China. Key Laboratory of Flexible Electronics (KLOFE) \& Institute of Advanced Materials (IAM), Nanjing Tech University (NanjingTech), Nanjing 211800, China.

Institute for Lasers, Photonics and Biophotonics and the Department of Chemistry, University at Buffalo, State University of New York, Buffalo, New York 14260, USA.

"College of Physics and Optoelectronic Engineering, Shenzhen University, Shenzhen 518060, China.

\#Shaanxi Institute of Flexible Electronics (SIFE), Northwestern Polytechnical University (NPU), 127 West Youyi Road, Xi'an 710072, China.

\&Wenbo Hu and Xiaofei Miao contributed equally to this work.

*Address correspondence to: iamqlfan@njupt.edu.cn, tche@szu.edu.cn, and pnprasad@buffalo.edu. 


\section{Supporting Figure}

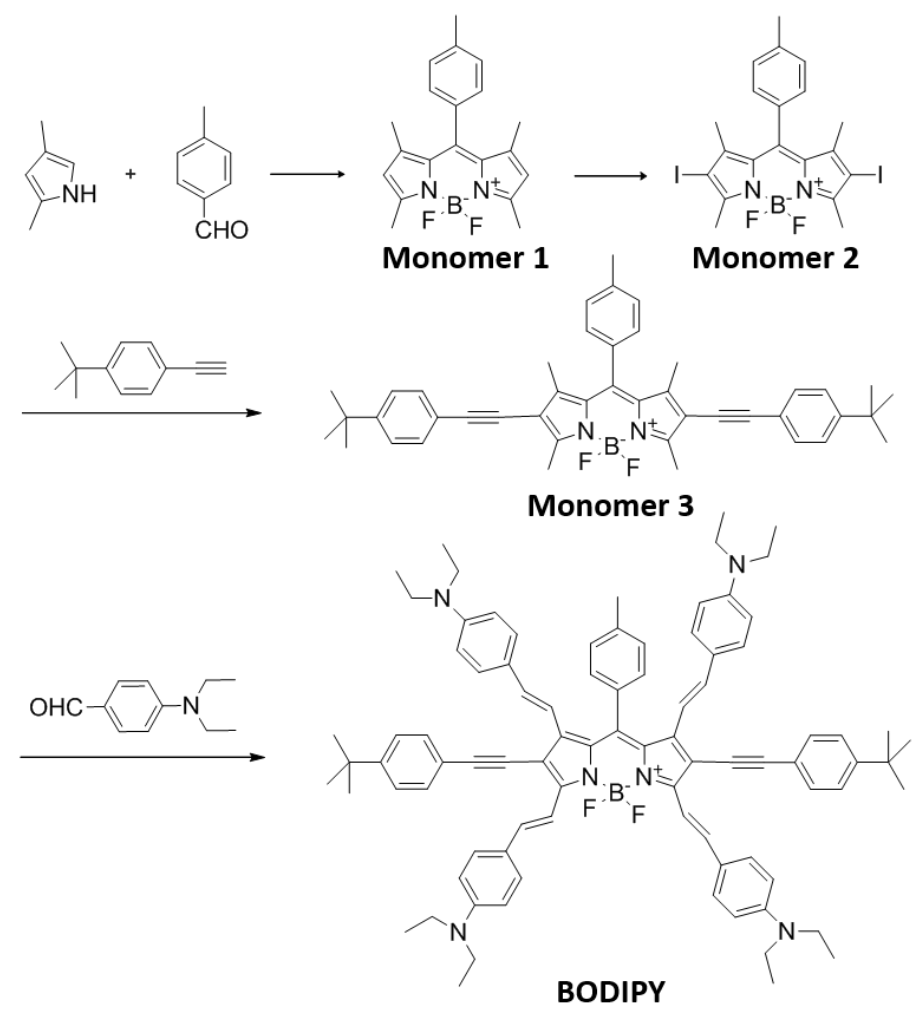

Scheme S1. Synthetic routes for BDP dye.

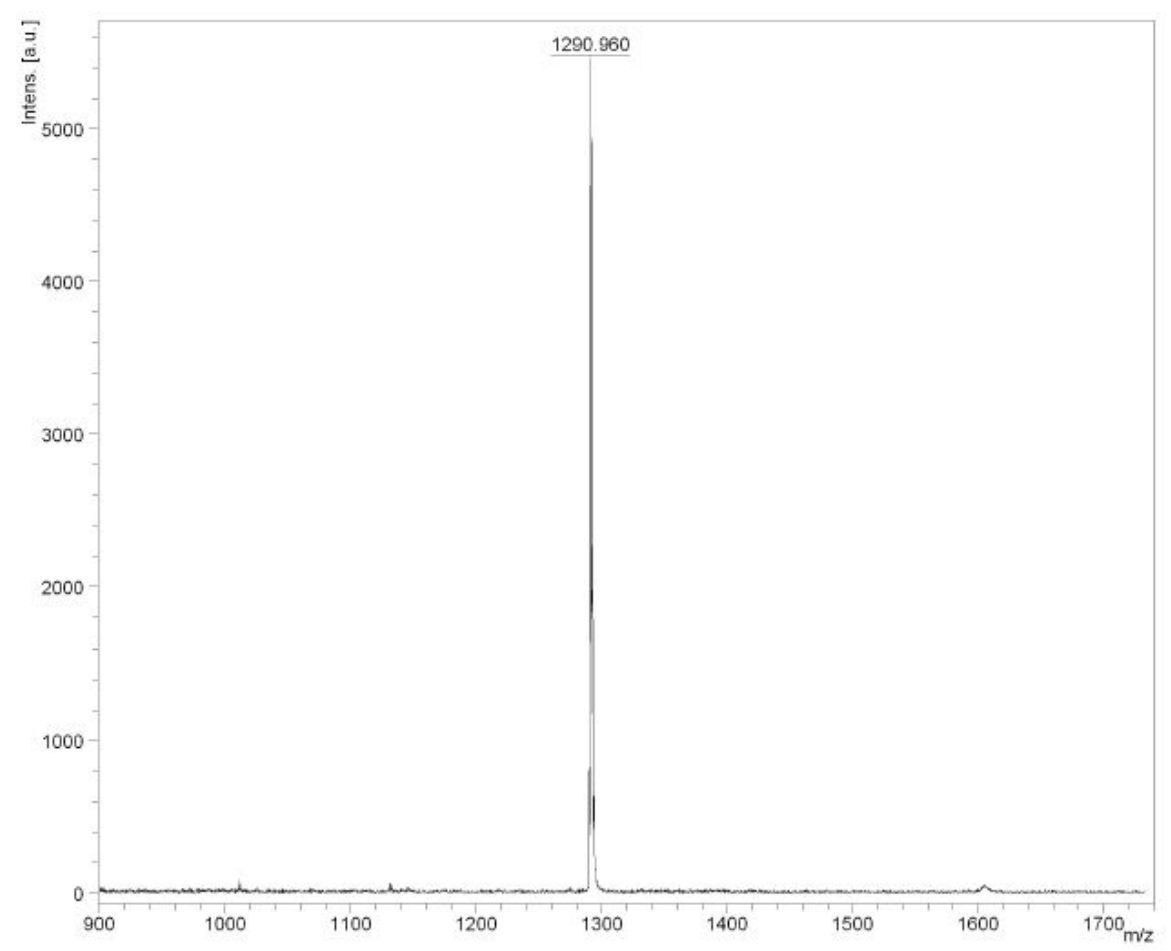


Figure S1. High resolution mass spectrometry (HRMS) chart of BDP dye.
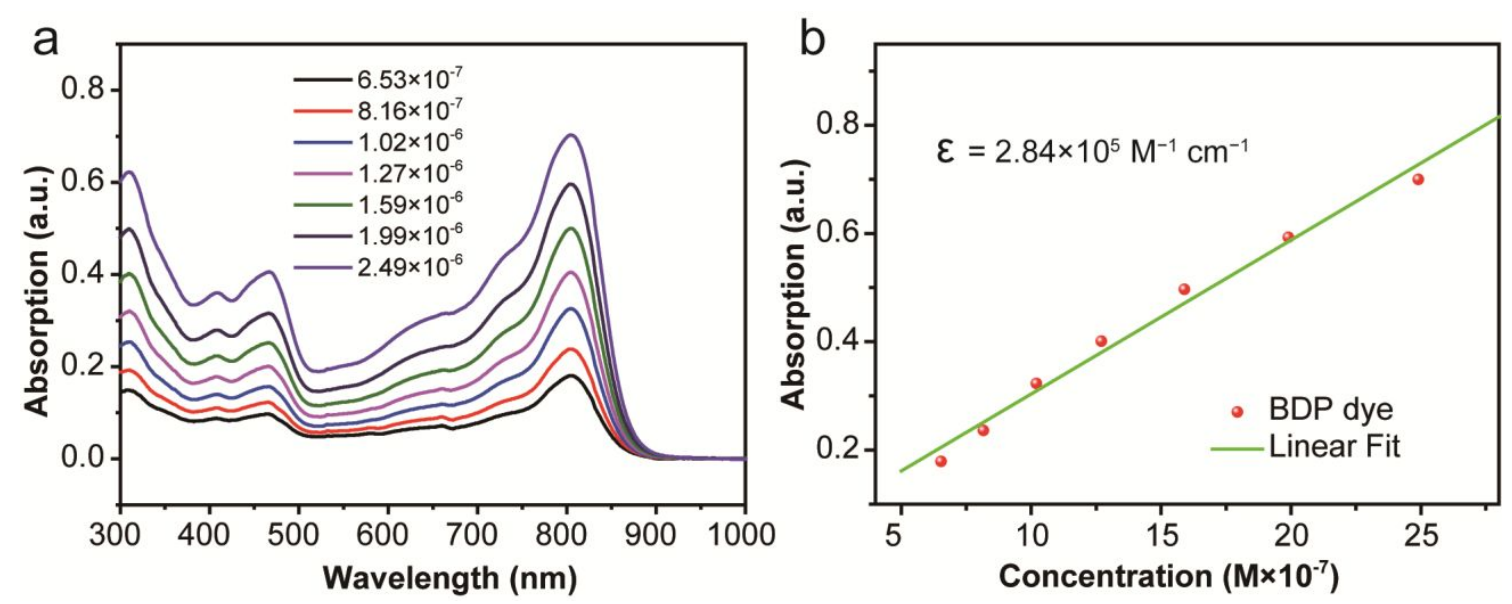

Figure S2. Concentration dependence of the absorption of BDP dye in THF. (b) The plot of optical density at $808 \mathrm{~nm}$ versus concentration. The straight line is a linear least-squares fit to the data, indicating the effective molar extinction coefficient of the BDP dye at the absorption maxima.

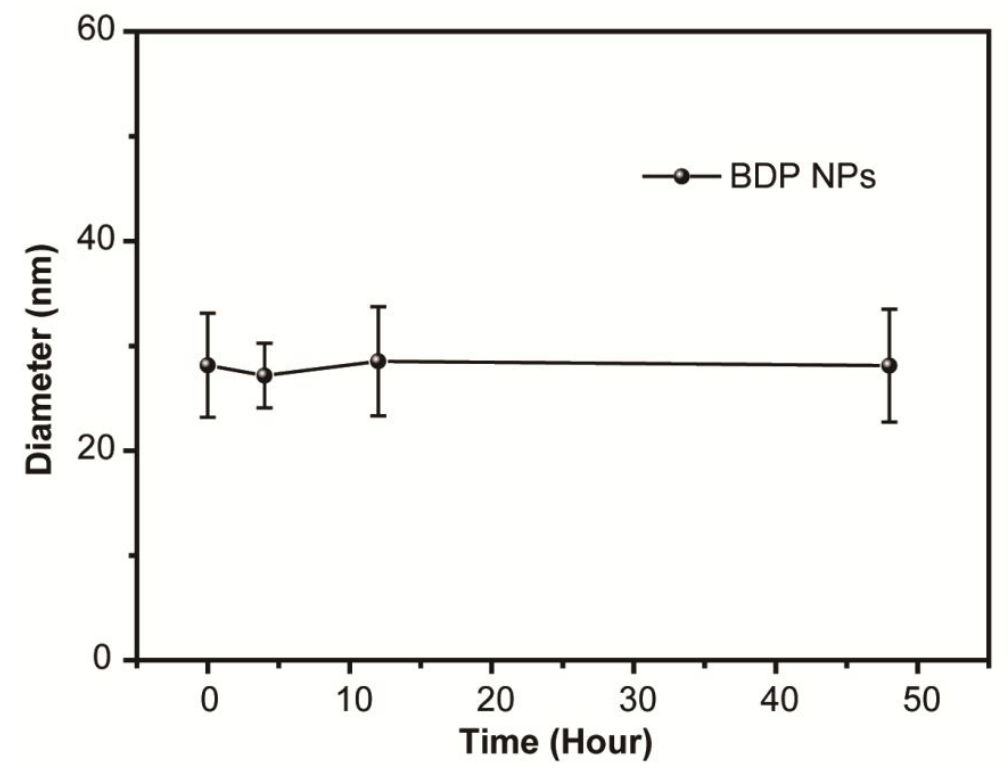

Figure S3: Stability of the BDP NPs hydrodynamic size after different incubation periods with serum. Error bars indicated standard deviation of 3 independent measurements. After 48 $\mathrm{h}$ incubation, all hydrodynamic sizes of BDP NPs still retained at around $30 \mathrm{~nm}$, indicating excellent long-term stability of BDP NPs even in physiological conditions. 


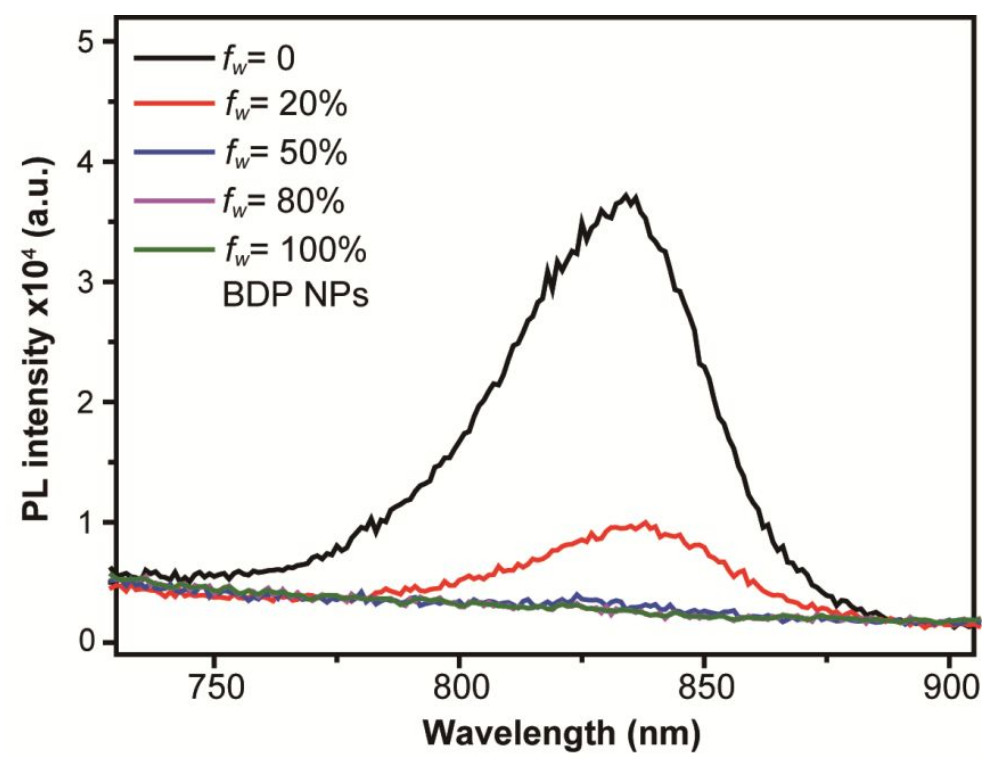

Figure S4. PL spectra of the BDP dye in THF-water mixtures with different water fractions $\left(f_{w}\right)$. PL intensity decreases withan increase of water fraction $\left(f_{w}\right)$, indicative of a substantial transition of emissive state to a dark state under aggregation.

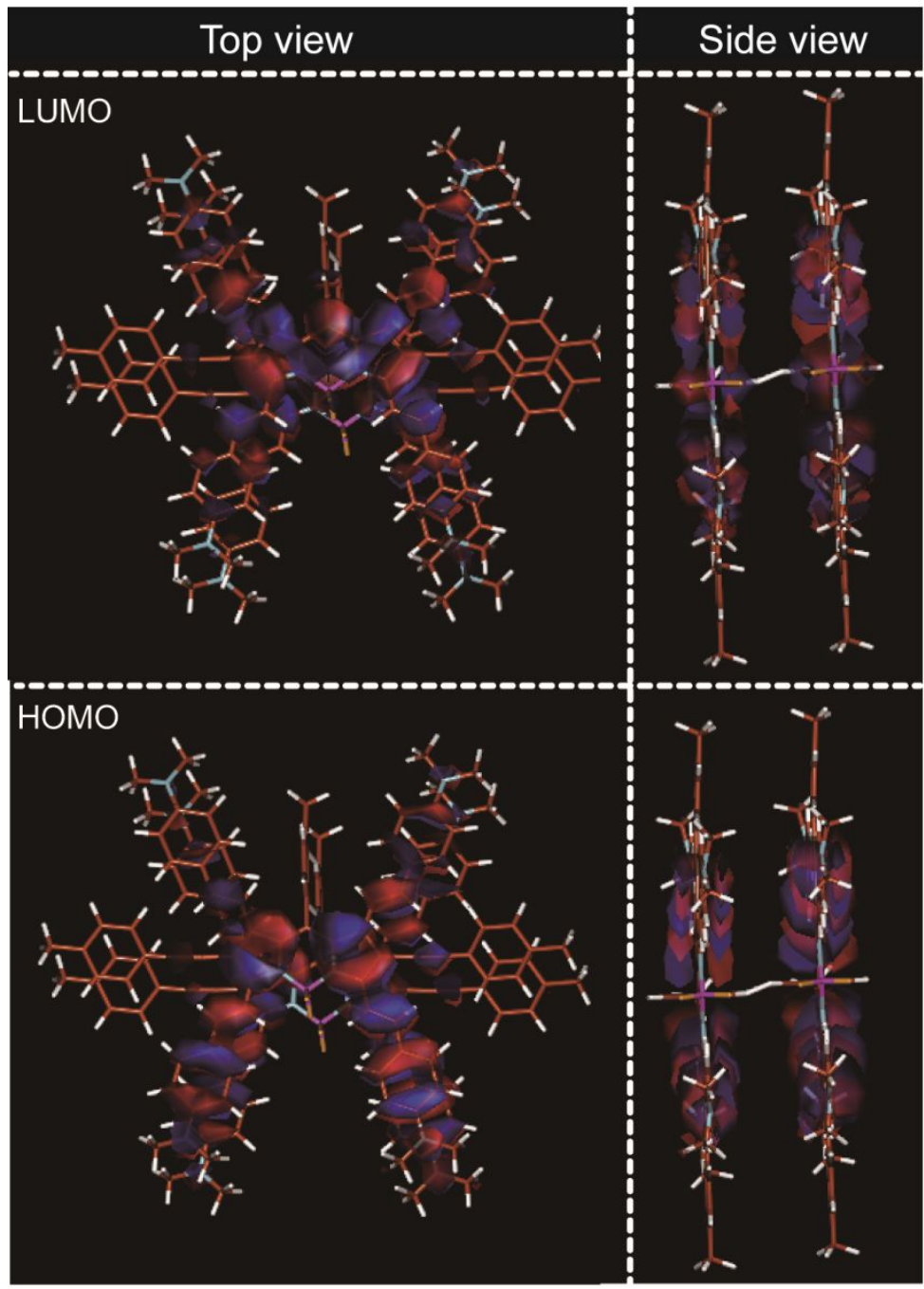


Figure S5. Frontier molecular orbitals of the BDP with parallel ladder-like $\pi-\pi$ stacking (Hdimer).

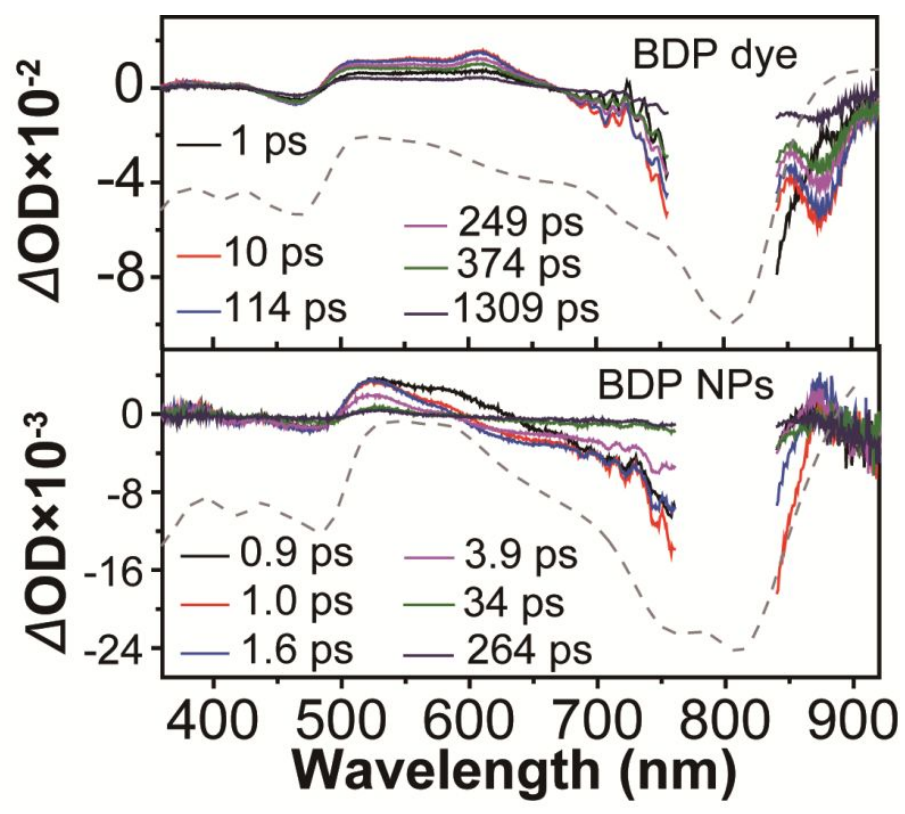

Figure S6 fs-TA spectra of the BDP dye and NPs at selected decay times. The insert dash line represents the corresponding steady-state absorption spectrum, whose profile is very similar with its fs-TA spectrum around $800 \mathrm{~nm}$. Therefore, we assigned the absorption band around $800 \mathrm{~nm}$ to the ground state bleaching (GSB).

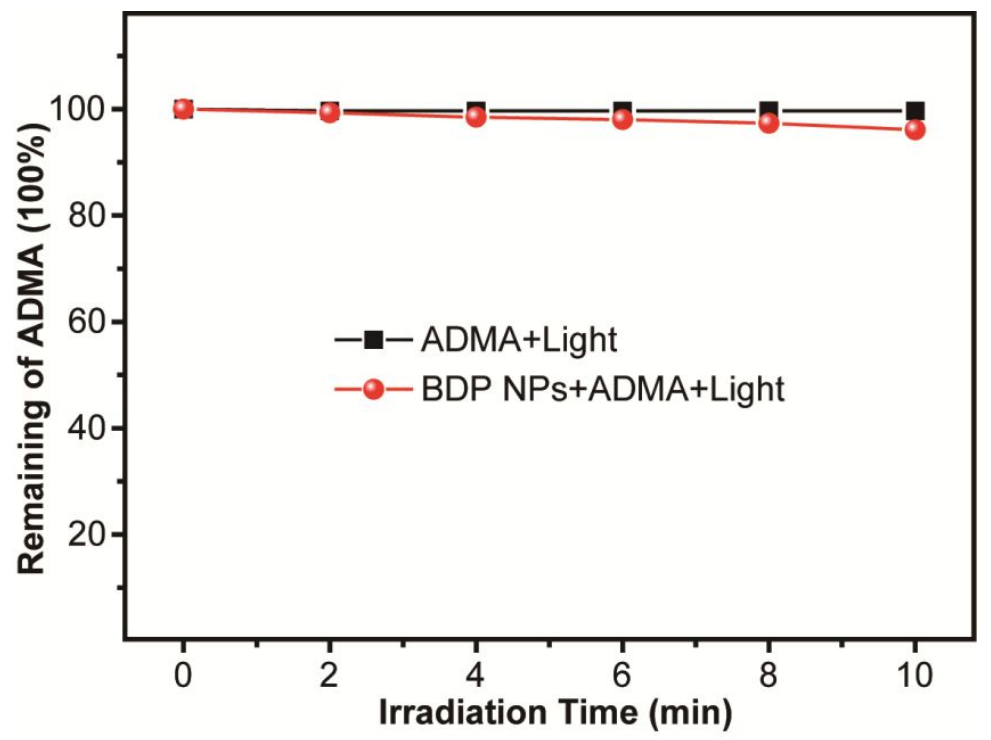

Figure S7. Percentage of the unreacted ${ }^{1} \mathrm{O}_{2}$ chemical trap (anthracene-9,10-diyl-bismethylmalonate, ADMA) in the presence of different samples. The negligible ADMA consumption of BDP NPs demonstrates an absence of triplet-photosensitization, implying that a negligible nonradiative ISC process occurs in BDP NPs. 


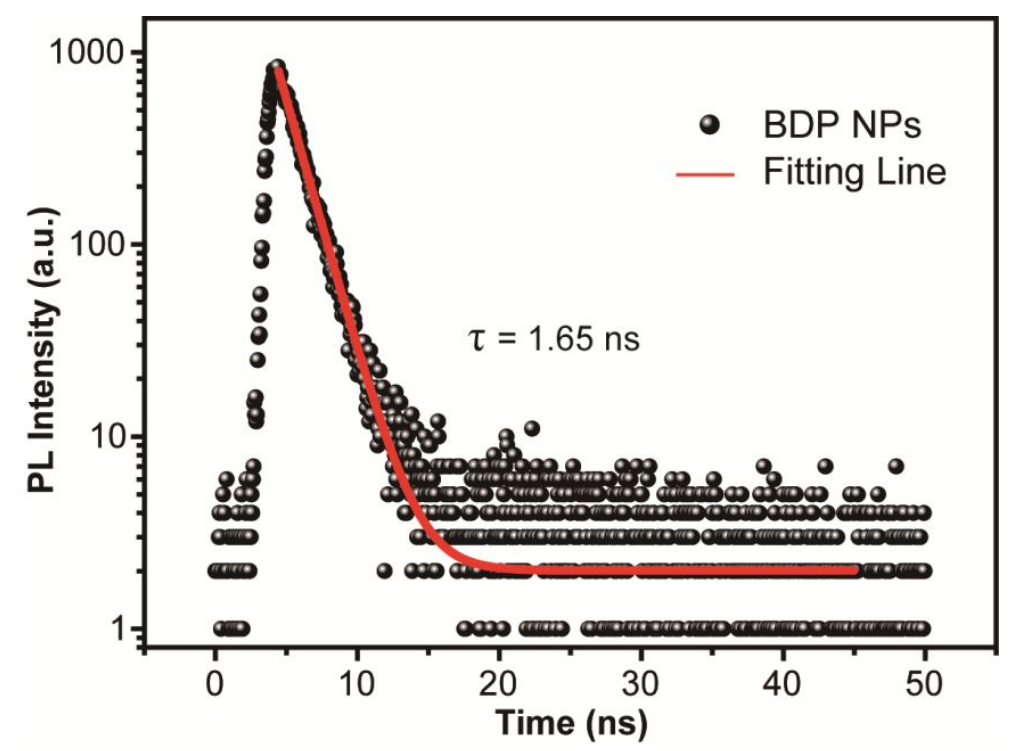

Figure S8. Transient fluorescence spectroscopy of BDP NPs in aqueous solution, monitoring at $865 \mathrm{~nm}$ and excitation wavelength at $780 \mathrm{~nm}$ (Pulsewidth: $6 \mathrm{ps}$, repetition: $20 \mathrm{MHz}$ ).

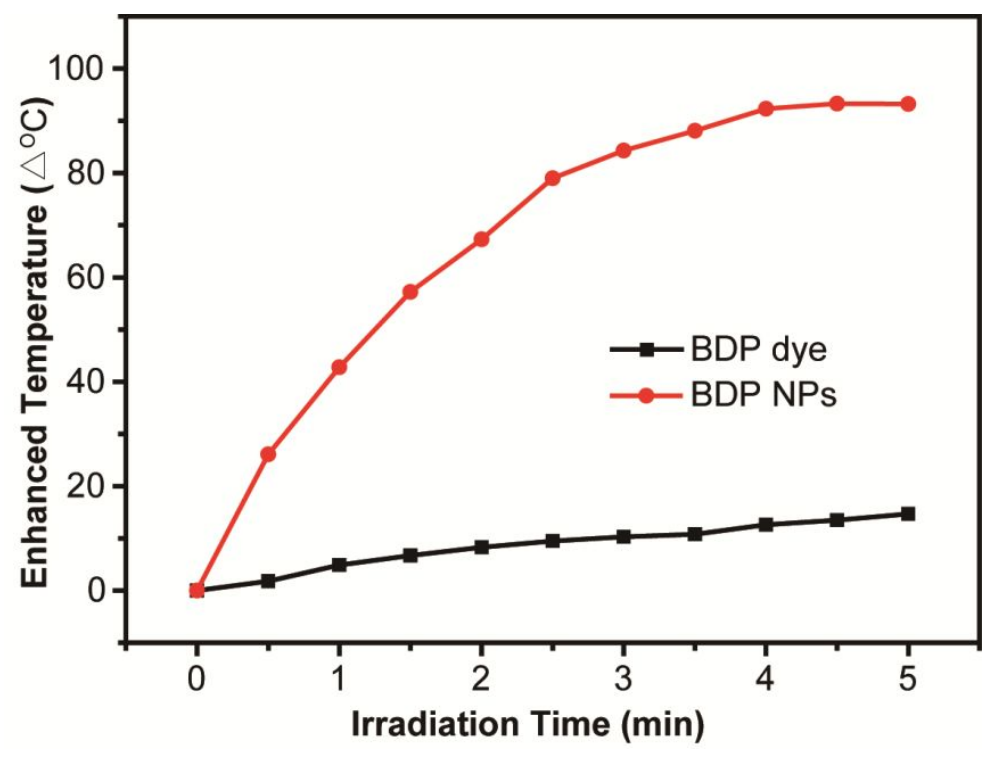

Figure S9. Temperatures elevation by the BDP dye in THF and BDP NPs in aqueous solution $\left(200 \mu \mathrm{g} \mathrm{mL}^{-1}\right)$ as a function of $808 \mathrm{~nm}$ laser irradiating time $\left(0.5 \mathrm{~W} \mathrm{~cm}^{-2}\right)$. The huge temperature increase in BDP NPs indicates a better photothermal effects of BDP NPs relative to isolated BDP. 


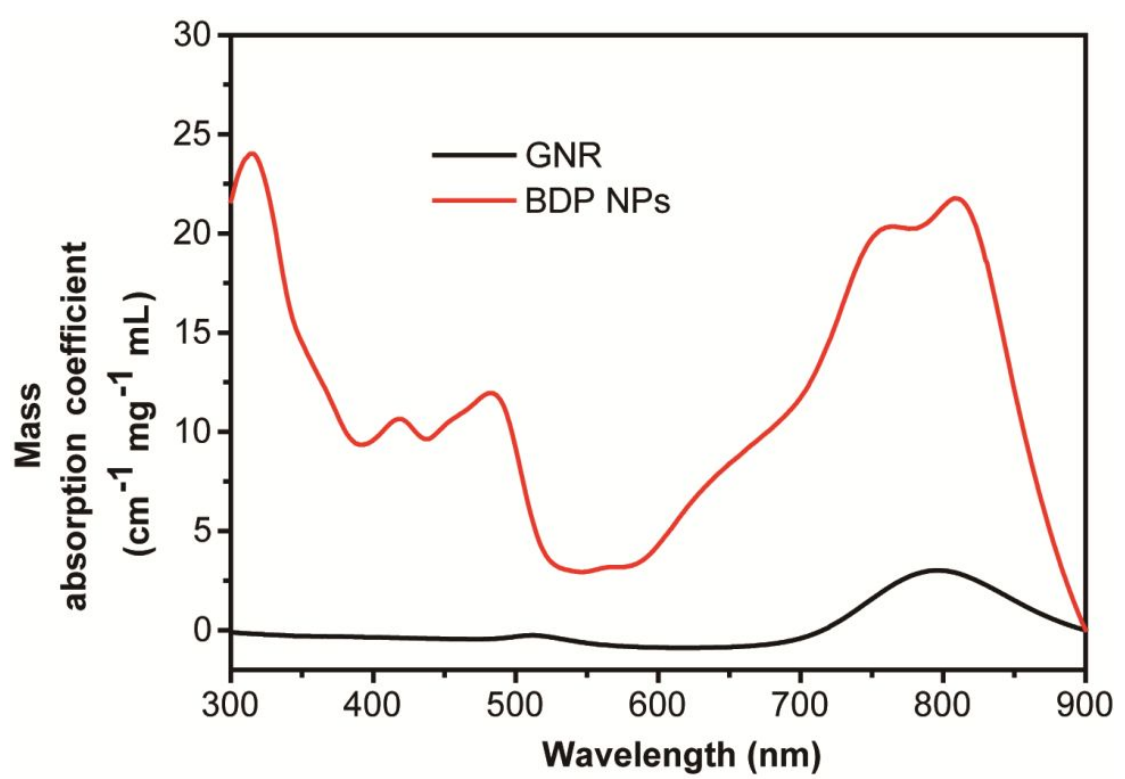

Figure S10. Absorption spectra of BDP NPs and GNR.
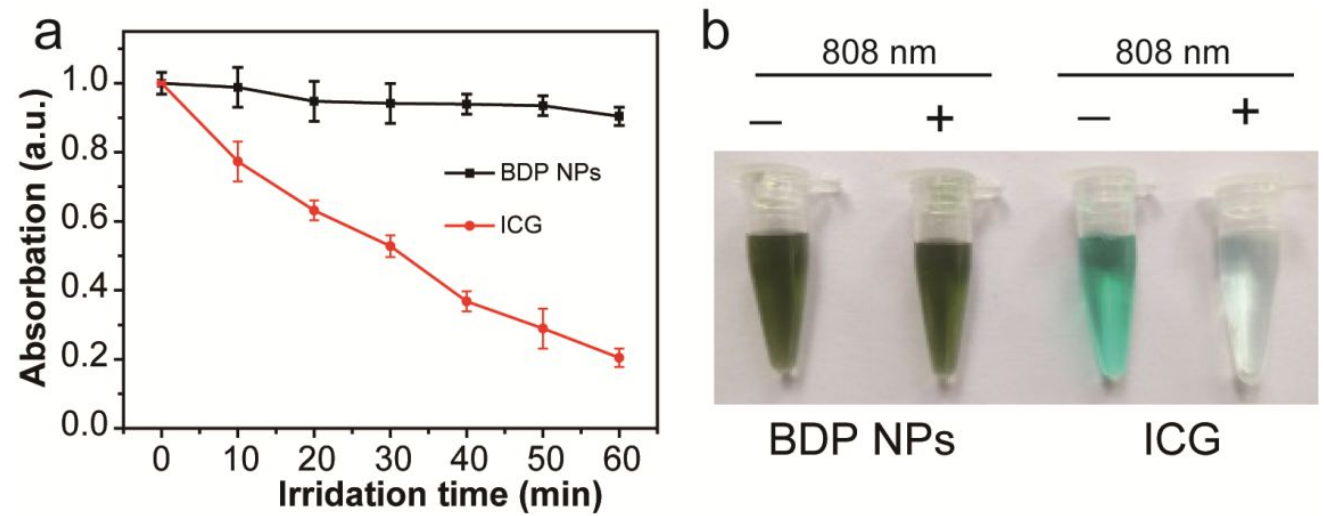

Figure S11. (a) Photostability of BDP NPs and commercial Indocyanine green (ICG) under irradiation at $808 \mathrm{~nm}$ laser (laser density of ca. $500 \mathrm{~mW} \mathrm{~cm}^{-1}$ ). (b) Digital photos of BDP NPs and ICG before and after $60 \mathrm{~min}$ irradiation. BDP NPs show unchanged absorption (Figure S9a) and negligible variation of color (Figure S11b) after $60 \mathrm{~min}$ of continuous laser irradiation at $808 \mathrm{~nm}$ (laser density of ca. $500 \mathrm{~mW} / \mathrm{cm}^{2}$ ), revealing an excellent absorption stability. 


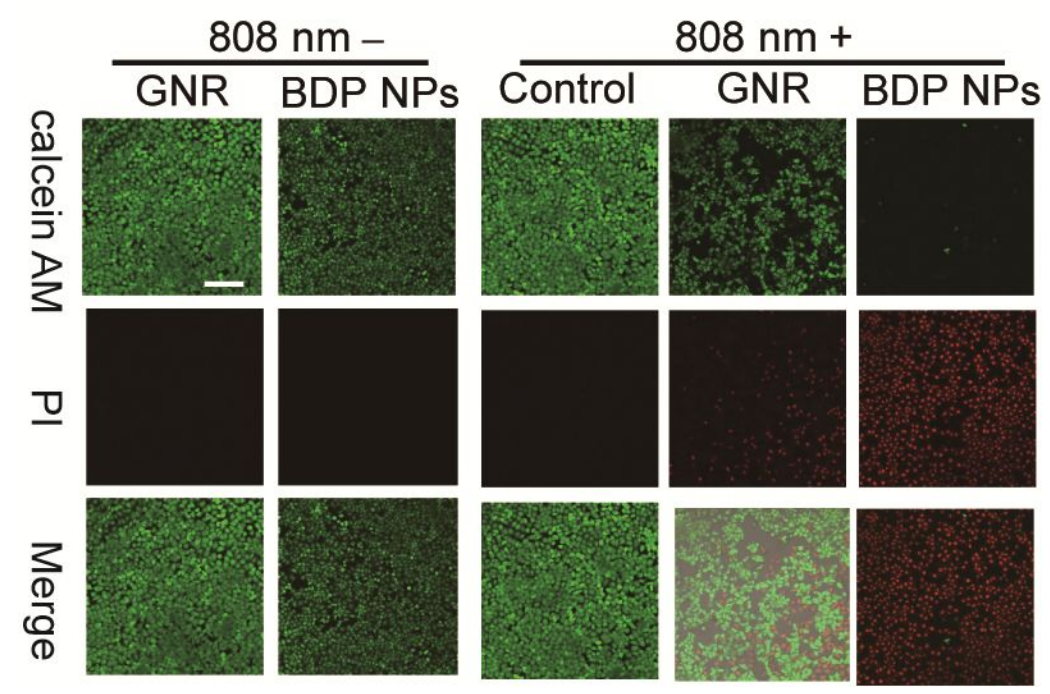

Figure S12. Confocal fluorescence images of BDP NPs or GNR-incubated HeLa cancer cells after laser irradiation at $808 \mathrm{~nm}\left(0.3 \mathrm{~W} / \mathrm{cm}^{2}\right)$ for $5 \mathrm{~min}$. The cells were co-stained with calcein AM and propidium iodide (PI). Scale bars: $200 \mu \mathrm{m}$. Green color represents live cells, and red color represents dead cells.

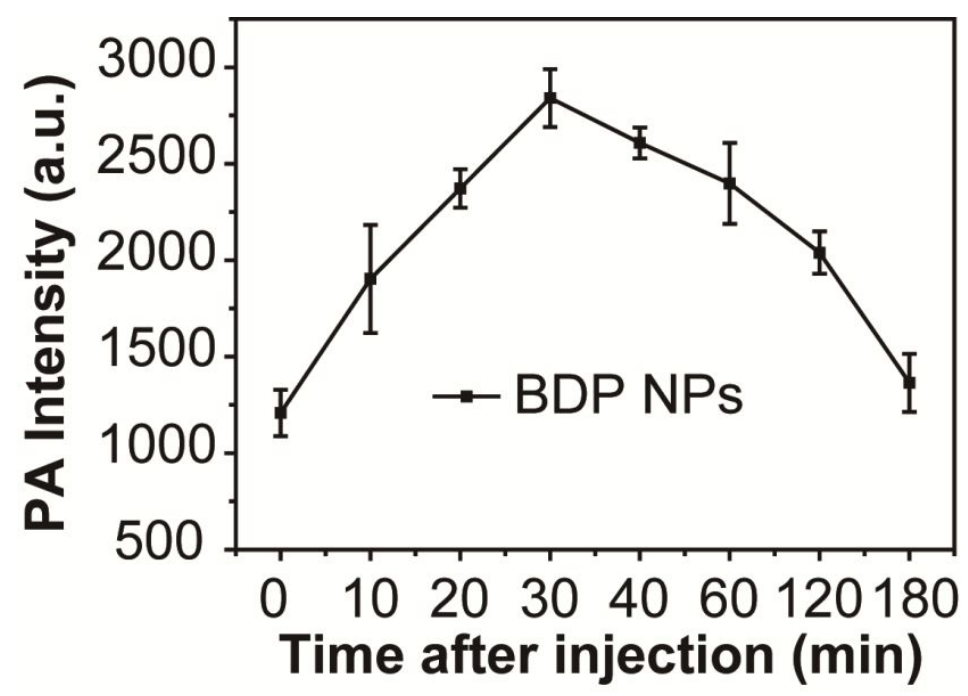

Figure S13. Quantification of the PAI intensity of BDP NPs at tumor site as a function of post-injection time. 

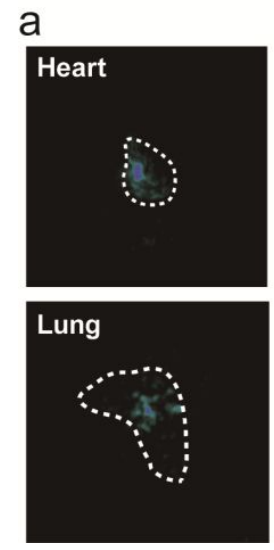
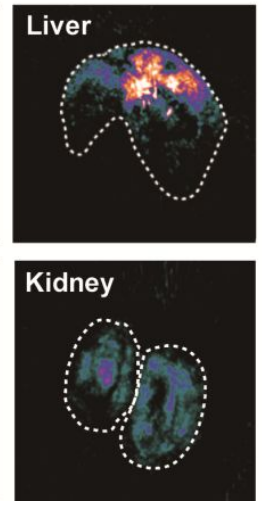
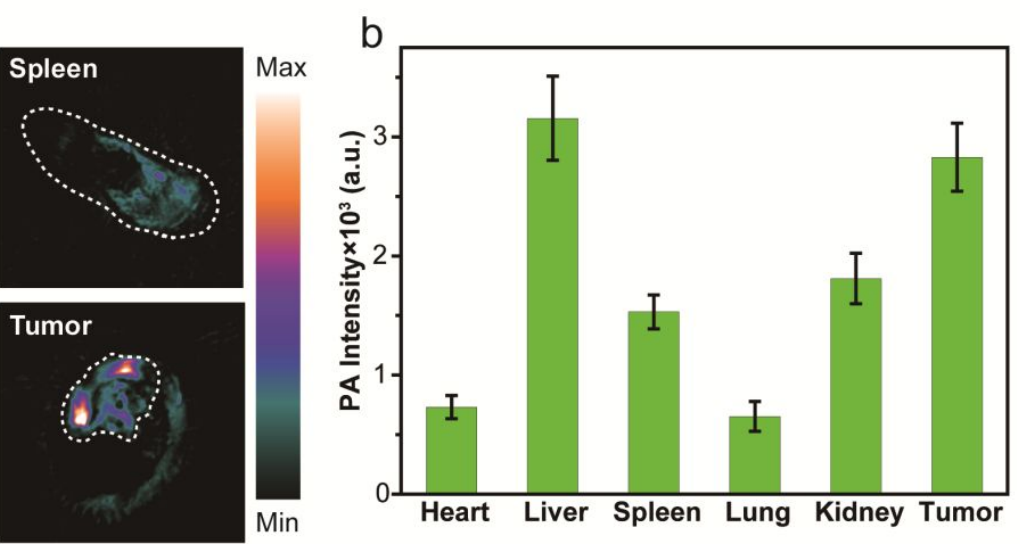

Figure S14. Ex vivo (a) photoacoustic (PA) imaging and PA quantification (b) of BDP NPs in major organs of mice after $2 \mathrm{~h}$ systemic administration. Error bars were based on standard error of mean $(n=4)$. The PA data were acquired under excitation at $800 \mathrm{~nm}$.

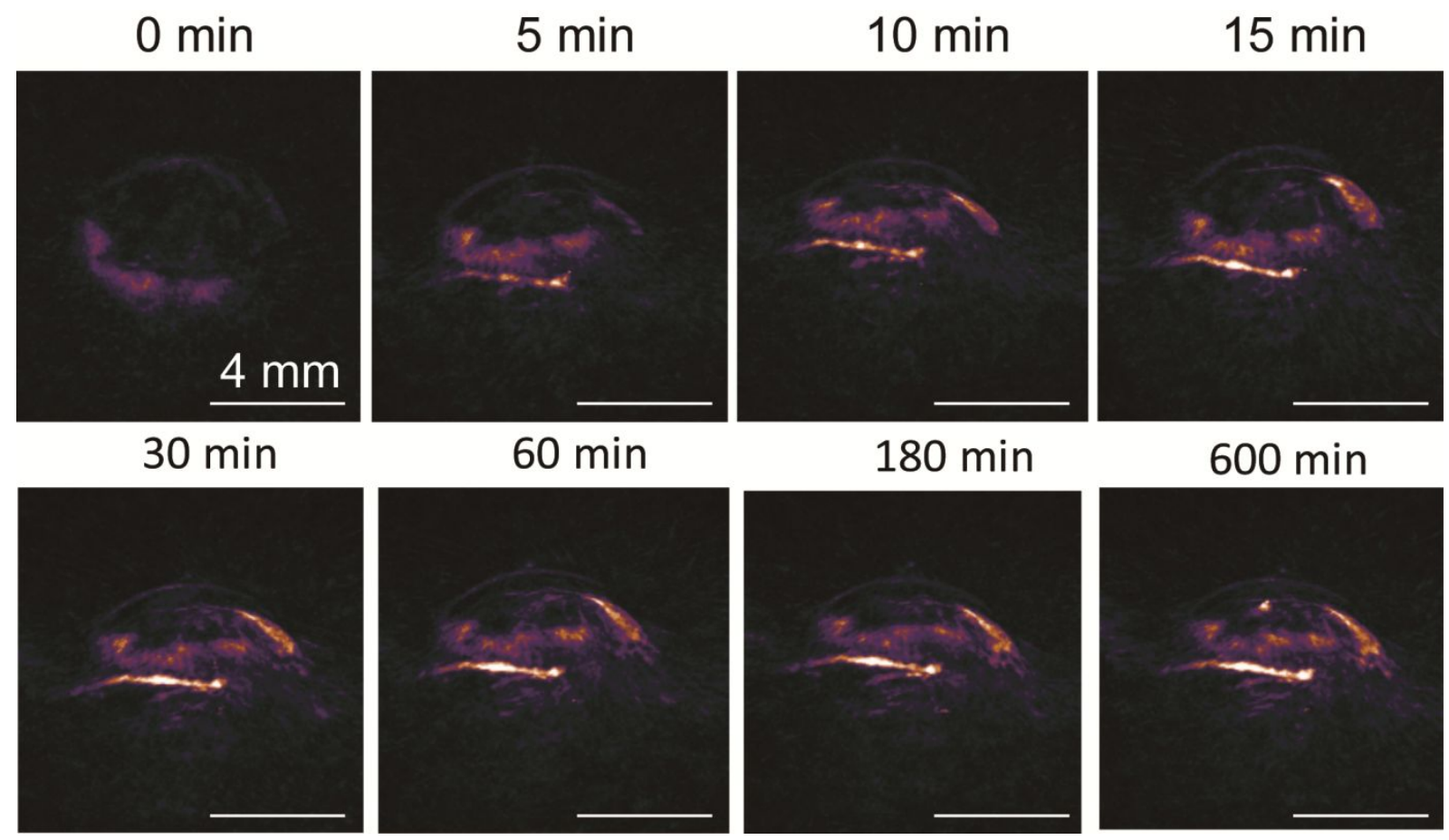

Figure S15. Real-time PAI of mice after systemic administration of GNR $(200 \mu \mathrm{L}, 150$ $\mu \mathrm{L} / \mathrm{mL}$ ) through intravenous injection. GNR displays rapid accumulation at the tumor site after $30 \mathrm{~min}$ of injection and maintains moderate accumulation up to $600 \mathrm{~min}$, suggesting a considerably slower clearance. 


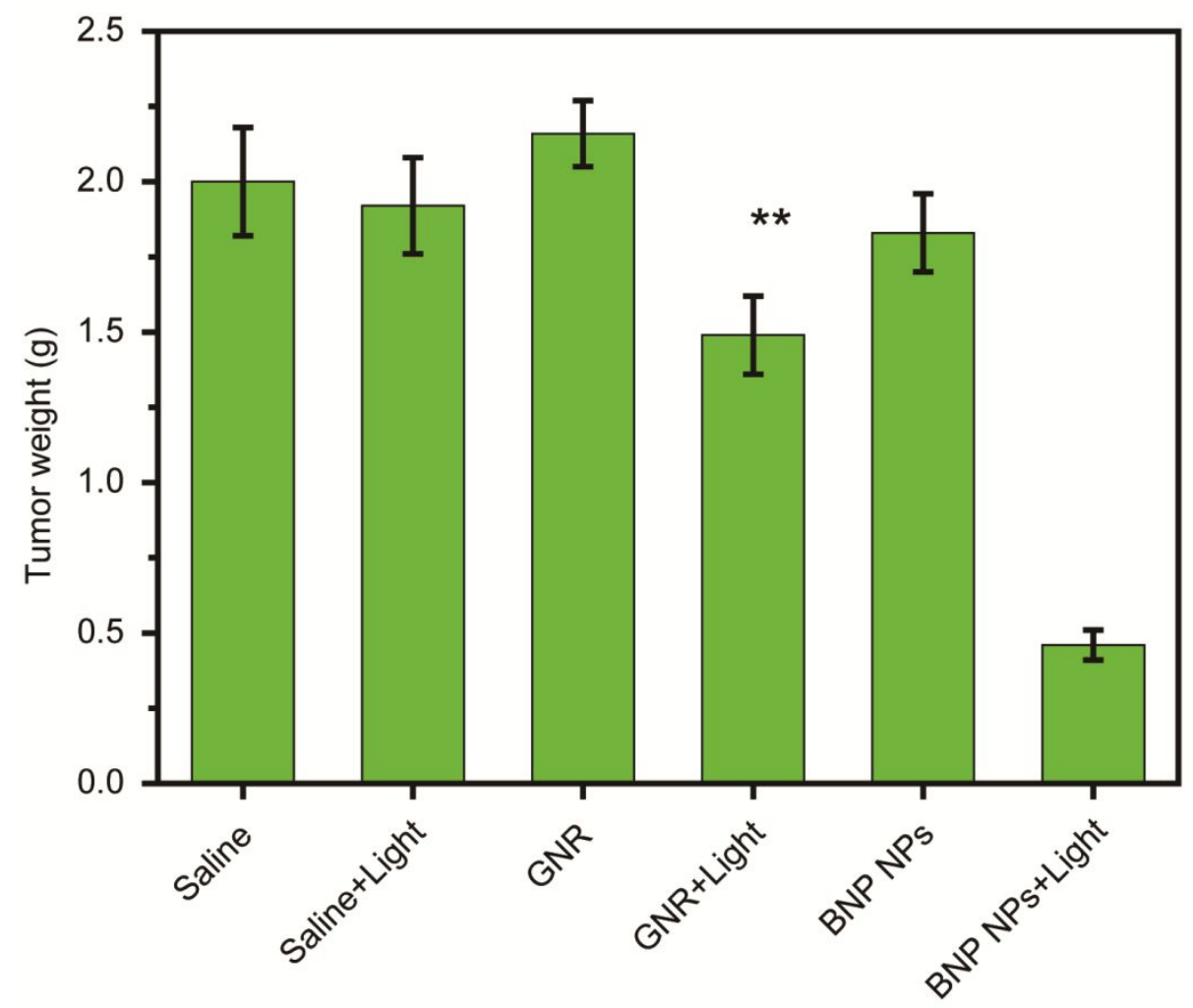

Figure S16. Weights of tumors in mice sacrificed after 16-day observation. Results are presented as mean \pm S.D., $\mathrm{n}=6 * \mathrm{P}<0.05, * * \mathrm{P}<0.01$.

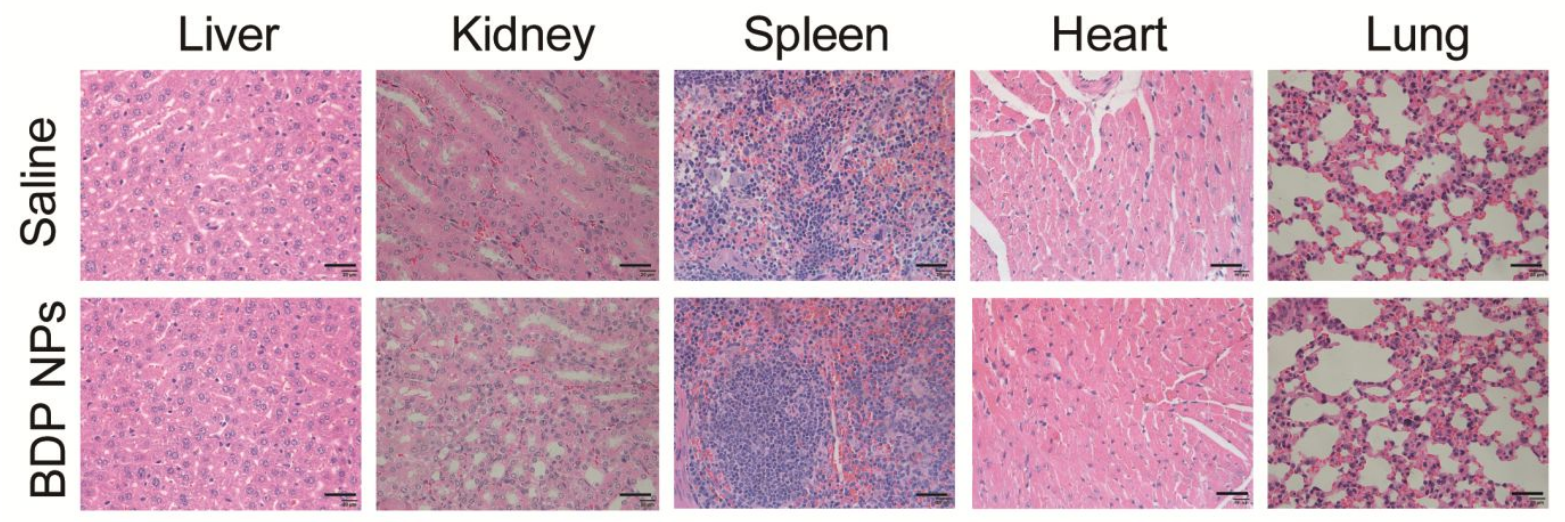

Figure S17. Histological H\&E staining for main organs at day 16 after the photothermal treatment with saline and BDP NPs. Scale bars: $40 \mu \mathrm{m}$.

\section{Experimental Section}

Synthesis of BDP dye. Monomer 1, 2, 3 were synthesized according to our previous synthesis methods. ${ }^{1}$ Monomer 3 (1.3 g, $\left.1 \mathrm{mmol}\right)$, 4- (diethylamino)benzaldehyde (3.54 g, $\left.10 \mathrm{mmol}\right)$, dry toluene $(40 \mathrm{~mL})$, acetic acid $(5 \mathrm{~mL})$, and piperidine $(5 \mathrm{~mL})$ were added in a $100 \mathrm{~mL}$ roundbottomed flask. The solution was heated at $120^{\circ} \mathrm{C}$ under reflux for $72 \mathrm{~h}$ in a Dean-Stark 
apparatus to remove water generated by condensation. The mixture was cooled to room temperature, washed with saturated aqueous $\mathrm{NaHCO}_{3}$ solution $(350 \mathrm{~mL})$, extracted from $\mathrm{CH}_{2} \mathrm{Cl}_{2}(3 \times 500 \mathrm{~mL})$ and dried over $\mathrm{Na}_{2} \mathrm{SO}_{4}$. The solution was evaporated on a rotary evaporator, then the crude products were further purified by column chromatography on silica with petroleum ether/ $\mathrm{CH}_{2} \mathrm{Cl}_{2}=2: 1$. The final product was dried to yield a dark green powder (Yield: $0.32 \mathrm{~g}, 20 \%) .{ }^{1} \mathrm{H}$ NMR $\left(400 \mathrm{MHz}, \mathrm{CDCl}_{3}\right) \delta 8.56$ (d, $\left.J=15.9 \mathrm{~Hz}, 2 \mathrm{H}\right), 7.74$ (dd, $J=$ 16.2,6.5Hz, 4H), 7.64 (d, $J=9.0 \mathrm{~Hz}, 4 \mathrm{H}), 7.50$ (d, $J=8.4 \mathrm{~Hz}, 6 \mathrm{H}), 7.40$ (d, $J=8.4 \mathrm{~Hz}, 6 \mathrm{H})$, $6.87(\mathrm{~d}, J=8.8 \mathrm{~Hz}, 4 \mathrm{H}), 6.76(\mathrm{dd}, J=45.4,8.7 \mathrm{~Hz}, 4 \mathrm{H}), 6.56(\mathrm{~d}, J=8.9 \mathrm{~Hz}, 4 \mathrm{H}), 5.81$ (d, $J=$ $16.0 \mathrm{~Hz}, 2 \mathrm{H}), 3.44$ (ddd, $J=25.7,14.0,6.9 \mathrm{~Hz}, 16 \mathrm{H}), 2.65$ (s, 3H), 1.36 (s, 18H), 1.24 (dd, $J$ $=10.1,7.1 \mathrm{~Hz}, 24 \mathrm{H}) .{ }^{13} \mathrm{C} \mathrm{NMR}\left(101 \mathrm{MHz}, \mathrm{CDCl}_{3}\right) \delta 150.80,148.47,147.42,141.58,140.54$, 138.81, 133.99, 130.18, 129.54, 128.13, 125.04, 124.74, 121.64, 116.82, 111.61, 98.23, 86.84, $65.50,44.55,34.89,32.12,31.10,30.06,29.71,29.42,22.86,21.14,14.26,12.90$. MALDITOF-MS (m/z): calcd for $\mathrm{C}_{88} \mathrm{H}_{97} \mathrm{BF}_{2} \mathrm{~N}_{2}[\mathrm{M}+4 \mathrm{H}]^{+}, 1290.78$; found, 1290.96 .

Photothermal conversion efficiency. The photothermal conversion efficiency was calculated by the following formula:

$$
\mathrm{\eta}=\frac{\mathrm{hS}\left(T_{\text {Max }}-T_{\text {surr }}\right)-Q_{\text {Dis }}}{I\left(1-10^{-A_{\lambda}}\right)}
$$

where $h$ represents the heat-transfer coefficient, $\mathrm{S}$ represents the surface area of the container, $\mathrm{T}_{\mathrm{Max}}$ represents the equilibrium temperature (the highest temperature the sample can reach with a laser irradiation), $\mathrm{T}_{\text {Surr }}$ represents the surrounding temperature, $\mathrm{Q}_{\text {Dis }}$ is the baseline energy input of the sample cell and the $A_{\lambda}$ is the absorbance of nanoparticles at $\lambda$ of $808 \mathrm{~nm}$.

Confocal Imaging of Photoinduced Cell Death. The Hela cells were seeded in the culture plates at $37^{\circ} \mathrm{C}$ for $24 \mathrm{~h}$, and then the cells were washed once with PBS. DMEM medium (2 $\mathrm{mL})$ with BDP NPs or GNR $(10 \mu \mathrm{g} / \mathrm{mL})$ was added. After the cells were further cultured for 4 $\mathrm{h}$, the cells were stained with Calcein-AM and PI (Life Technologies Corporation), the plates were exposed to $808 \mathrm{~nm}$ laser irradiation $\left(0.3 \mathrm{~W} / \mathrm{cm}^{2}\right)$ for $5 \mathrm{~min}$, and then they were inculcated another $4 \mathrm{~h}$ for apoptosis. Cell death imaging was visualized with an invertingtyped laser scanning confocal microscope in the time-lapse mode. Under the excitation wavelength at $488 \mathrm{~nm}$, collecting ranges were 500-550 nm for Calcein-AM emission and 600$650 \mathrm{~nm}$ for PI emission, respectively.

\section{REFERENCES}

(1) Hu, W.; Ma, H.; Hou, B.; Zhao, H.; Ji, Y.; Jiang, R.; Hu, X.; Lu, X.; Zhang, L.; Tang, Y.; Fan, Q.; Huang, W. Engineering Lysosome-Targeting Bodipy Nanoparticles for 
Photoacoustic Imaging and Photodynamic Therapy under Near-Infrared Light. ACS Appl. Mater. Interfaces 2016, 8, 12039-12047. 